\begin{tabular}{|c|c|}
\hline $\begin{array}{r}\text { Web Revista } \\
\text { ODIALETO }\end{array}$ & $\begin{array}{c}\text { Núcleo de Pesquisa e Estudos Sociolinguísticos e Dialetológicos - NUPESD } \\
\text { Laboratório Sociolinguístico de Lúnguas Não-Indo-europeias e Multilinguismo - LALIMU } \\
\text { ISSN: 2178-1486 • Volume } 11 \text { - Número 33 • Mar 2021 } \\
\text { doit http://dx.doi.org/ } 10.48211 / \text { sociodialeto.vlli33.34l }\end{array}$ \\
\hline
\end{tabular}

\title{
A VARIAÇÃO DA CONCORDÂNCIA NOMINAL DE NÚMERO EM CARTAS PESSOAIS DE CORAÇÃO DE MARIA: ANÁLISE SINTAGMÁTICA E ATOMÍSTICA
}

THE VARIATION OF NOMINAL NUMBER AGREEMENT IN PERSONAL LETTERS FROM CORACÃO DE MARIA: SYNTAGMATIC AND ATOMISTIC ANALYSIS

\author{
Patrícia Santos de Jesus Brito (UEFS/PPGEL) ${ }^{1}$ \\ patysantosjesus@hotmail.com
}

\author{
Mariana Fagundes de Oliveira Lacerda (UEFS/PPGEL/FAPESB) ${ }^{2}$ \\ marianafag@gmail.com
}

\begin{abstract}
RESUMO: Este artigo apresenta uma análise da variação da concordância nominal de número na perspectiva sintagmática e atomística, em uma documentação epistolar, de caráter pessoal, escrita no decorrer do século XX, por redatores poucos escolarizados da região rural de Coração de Maria, interior baiano. A documentação em questão faz parte do banco de dados Corpus Eletrônicos de Documentos Históricos do Sertão (CE-DOHS), do Núcleo de Estudos de Língua Portuguesa (NELP), da Universidade Estadual de Feira de Santana (UEFS). Estes produtos gráficos são representativos das normas socialmente estigmatizadas ou populares do português brasileiro (PB), nos termos postulados por Lucchesi (2001, 2009, 2015) e Mattos e Silva (2004). Os referidos autores defendem que no processo sócio-histórico de formação dessa vertente do PB houve mudanças gramaticais induzidas devido ao intenso, abrupto e massivo contato entre línguas nos três primeiros séculos de colonização. O presente trabalho insere-se no escopo teórico metodológico da Linguística Histórica sócio-história no sentido stricto por considerar os fatores linguísticos e extralinguísticos para a análise dos dados linguísticos (WEINREICH, LABOV E HERZOG [1972] 2006), e também no sentido lato por trabalhar com corpus datado e localizado (MATTOS E SILVA, 2008). A análise dos dados encontrados identificou o perfil da variação da concordância nominal no corpus, com destaque para as variáveis linguísticas e sociais que a condicionam.
\end{abstract}

PALAVRAS- CHAVE: Contato linguístico. Cartas Marienses. Concordância nominal. Perspectiva sintagmática. Perspectiva atomística.

\begin{abstract}
This article presents an analysis of the variation of the nominal number agreement in the syntagmatic and atomistic perspective, in a personal, epistolary documentation, written during the 20th century, by poorly educated writers from the rural region of Coração de Maria, in the interior of Bahia. The documentation in question is part of the database Electronic Corpus of Historical Documents of the Sertão (CE-DOHS), of the Portuguese Language Studies Center (NELP), of the State University of Feira de Santana (UEFS). These graphic products are representative of the socially stigmatized or popular norms of Brazilian Portuguese (PB), in the terms evidenced by Lucchesi $(2001,2009,2015)$ and Mattos e Silva (2004). These authors argue that in the socio-historical process of formation of this aspect of PB there were changes grammatically induced due to the intense and massive contact between languages in

\footnotetext{
${ }^{1}$ Mestra em Estudos Linguísticos pelo Programa de Pós-graduação em Estudos Linguísticos da UEFS, Especialista em Estudos linguísticos e ensino aprendizagem de Língua portuguesa e licenciada em Letras vernáculas pela UEFS.

2 Professora adjunta do Departamento de Letras e Artes da Universidade Estadual de Feira de Santana /UEFS/Bahia/Brasil.
} 
the first three centuries of colonization. The present work falls within the theoretical and methodological scope of sociocultural historical linguistics in the strict sense by considering linguistic and extralinguistic factors for the analysis of linguistic data (WEINREICH, LABOV AND HERZOG [1972] 2006), and in the broad sense by working with dated and localized corpus (MATTOS E SILVA, 2008). The analysis of the data found identified the profile of the variation of the nominal agreement in the corpus, with emphasis on the linguistic and social variables that condition it.

KEYWORDS: Linguistic contact. Marienses Letters. Nominal agreement. Syntagmatic perspective. Atomistic perspective.

\section{INTRODUÇÃO}

A realidade linguística brasileira, hoje é definida nos termos de Lucchesi (2001), como sendo polarizada. Segundo o autor, esse sistema polarizado é constituído por dois grandes subsistemas denominados de normas cultas e normas populares.

As normas cultas refletem os padrões linguísticos da elite colonial portuguesa e foram transmitidas através do processo de escolarização. Por outro lado, as normas populares definem os padrões linguísticos da maioria da população brasileira e refletem as nuances do processo sócio-histórico de formação da sociedade brasileira, sobretudo por conta do empreendimento colonizador que submeteu milhares de indígenas e africanos escravizados a situações segregatícias e desumanas ${ }^{3}$. Estes contingentes populacionais falantes de milhares de línguas de diversas famílias e troncos linguísticos tiveram que aprender a língua do colonizador em situações adversas, desencadeando um processo de transmissão linguística irregular (TLI). (LUCCHESI, 2001, 2009, 2015).

As inúmeras diferenças estruturais que o chamado português popular apresenta em relação ao português europeu resulta desse processo de TLI, desencadeado "[...] nas situações de contato entre línguas abrupto, massivo e radical, compreendendo a aquisição precária do português por parte de índios e africanos, a sua socialização entre esses segmentos e a sua nativização, a partir desse modelo defectivo [...]". Lucchesi, (2009, p. 53). Para o referido autor, o contato linguístico havido, sobretudo nos três primeiros séculos de colonização portuguesa “é, sem sombra de dúvida, o principal

\footnotetext{
${ }^{3}$ Conferir Lucchesi (2001, 2009, 2015), Mattos e Silva (2004)
} 
parâmetro histórico para a contextualização das mudanças linguísticas que afetaram o português brasileiro" (Lucchesi, p. 41).

A concordância nominal de número é um dos fenômenos variáveis do PB que reflete mudanças no paradigma da flexão que tem a sua explicação no contato entre línguas no processo de formação da sociedade brasileira. Segundo Lucchesi (2012. p. 58), o amplo e profundo quadro de variação no uso das regras de concordância nominal e verbal que se observa nas variedades rurais e populares do PB "constitui o reflexo mais notável do processo de transmissão linguística irregular de tipo leve que afetou o português do Brasil em função de sua aquisição imperfeita por milhões de escravos africanos e índios aculturados". Para o autor, "o grau de variação no emprego de tais mecanismos gramaticais pode ser tomado como um dos parâmetros para analisar a norma popular brasileira, distinguindo cada uma de suas variedades, em termos sóciohistóricos" (LUCCHESI, 2012, p. 58).

Neste trabalho, realizamos a análise da concordância nominal de número no sintagma nominal (SN), sob duas abordagens de análise: a sintagmática (ou não mórfica), que considera o SN inteiro como dado de análise e a atomística (ou mórfica), que considera cada elemento do SN como um dado de análise. O corpus da pesquisa é uma documentação epistolar de caráter pessoal, escrita no decorrer do século XX, pelos segmentos socialmente estigmatizados, da região rural semiárida baiana, que faz parte do banco de dados Corpus Eletrônico de documentos Históricos do Sertão (CEDOHS $)^{4}$. O corpus em questão, denominado Cartas Marienses são um dos poucos acervos do referido banco de dados que caracteriza a vertente popular do PB e traz as marcas que o contato linguístico produziu no passado. Lucchesi (2001).

A pesquisa aqui apresentada pretende contribuir para as reflexões sobre o fenômeno, sobretudo porque é esteada em corpus escrito de sincronias passadas por indivíduos com pouca escolarização.

\footnotetext{
${ }^{4}$ http://www5.uefs.br/cedohs/
} 


\section{ASPECTOS GERAIS DA CONCORDÂNCIA NOMINAL}

A concordância nominal de número, de modo geral, é denominada, tradicionalmente, em termos de reiteração de mesmo elemento morfológico - de gênero, número - que se inter-relacionam a certos elementos gramaticais sintática e semanticamente. Conforme afirma Brandão (2016), a reiteração desses elementos funciona como uma marca explícita ou redundante da dependência sintática ou semântica que tais elementos mantêm entre si. Nesse sentido, a concordância nominal é definida pela inter-relação morfossintático-semântica entre os constituintes do sintagma nominal.

Bechara, na obra Moderna Gramática Brasileira (1999, p. 543), afirma que "em português a concordância consiste em se adaptar a palavra determinante ao gênero, número e pessoa da palavra determinada". Dessa forma, a concordância nominal é "a que se verifica em gênero e número entre o adjetivo e o pronome, o artigo, o numeral ou o particípio e o substantivo ou pronome a que se referem" (BECHARA, 1999, p.543).

Diferente do que pressupõe a tradição gramatical, inúmeras pesquisas no âmbito da sociolinguística variacionista, referentes à concordância nominal de número, têm mostrado consideráveis padrões de variedades, levando se conta uma gama de constituintes que podem compor o sintagma nominal (SN), além de fatores linguísticos e extralinguísticos que exercem influência na sua realização.

De acordo com Scherre (1988), o termo concordância não seria o mais apropriado para todos os casos, já que em muitas situações, apenas um elemento do sintagma nominal é formalmente marcado. Segundo a autora, o mais correto seria falar em indicação de pluralidade. "Concordância gramatical implica harmonia formal em pelo menos dois elementos de uma dada construção" (SCHERRE, 1988, p. 64), o que de fato, não ocorre em alguns casos.

Diversos estudos sobre o $\mathrm{PB}$, tanto na perspectiva sincrônica contemporânea com corpora orais (SCHERRE, 1988; LOPES, 2001; entre outros), como em sincronias 
passadas em corpora escritos (OLIVEIRA, SOUZA E COELHO 2009, SANTOS, 2017), têm demostrado variação sistemática nos processos de concordância de número. Ou seja, a concordância nominal de número, dentro do SN, no Português Brasileiro, não é regra categórica, resulta na presença da forma binária: presença de marca formal de número plural em todos os elementos do sintagma nominal $\mathrm{X}$ ausência de marca formal de número plural em algum (uns) elemento(s) do $\mathrm{SN}$.

Há, portanto, de um lado, a regra geral que corresponde aos padrões normativos e que é prescrita pela tradição gramatical - que se caracteriza por colocar todas as marcas explícitas de plural em todos os elementos flexionáveis do sintagma nominal. E do outro lado, a regra de concordância-redundante, ou seja, os elementos do SN podem ou não apresentar marcas de pluralidade. Os contextos a seguir exibem as características do fenômeno.

(i) Na inserção da marca de plural em todos os elementos do SN

1. [...]que reci-|bir das tuas delicadas mãos | que a aceite [...] (JMO, C-56)

(ii) Na inserção da marcação de plural em alguns elementos

2. [...]reci-|bir das tuas delicadaØ mãoØ | que a aceite [...] (JMO, C-56)

(iii) Na inserção da marcação de plural num único elemento do $\mathrm{SN}$, geralmente o que reside na primeira posição (ou em outras posições)

3. [...]que reci-|bir das tuaØ delicadaØ mãoØ | que a a [...] (JMO, C-56)

Diante do que foi exposto, pode-se afirmar que a concordância nominal no PB, pode ter padrões variáveis e que essa variabilidade não ocorre aleatoriamente, mas de forma sistemática, regida por fatores linguísticos e sociais. O trabalho aqui proposto visa contribuir para uma melhor compreensão desse fenômeno, em especial por tratar de corpora escritos de sincronias passadas. 


\begin{tabular}{|c|c|}
\hline $\begin{array}{r}\text { Web Revista } \\
\text { ODIALETO }\end{array}$ & 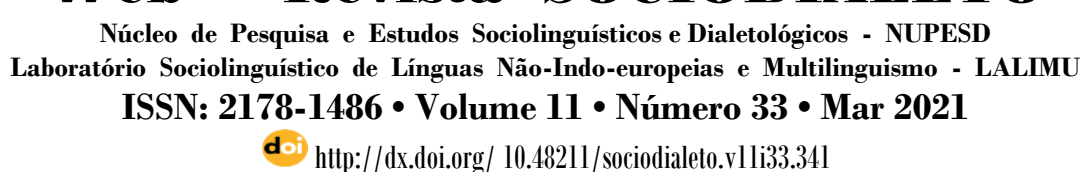 \\
\hline
\end{tabular}

\section{AS CARTAS MARIENSES}

O corpus Cartas Marienses faz parte do banco de dados Corpus Eletrônico de Documentos Histórico do Sertão (CE-DOHS), do projeto vozes do sertão em dados povos, história e formação do português brasileiro, um dos projetos do Núcleo de Estudos de Língua Portuguesa (NELP), da Universidade Estadual de Feira de Santana. O referido acervo - constituído por 67 cartas, 17 cartões e 5 bilhetes - trata-se de uma documentação epistolar, de caráter pessoal, escrita no período que vai de 1935 a 1995 , por 29 redatores com pouca escolarização da região rural de Coração de Maria, município baiano. A seguir, fac-símile de uma das cartas do acervo:

Figura 1: Fac-símile da carta $n^{\circ} 52$, do acervo Cartas Marienses.

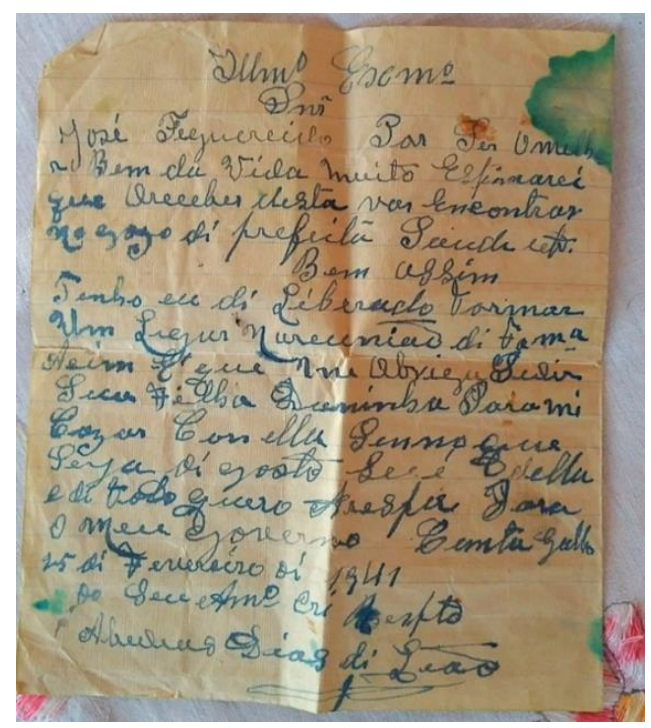

Fonte: CE-DOHS/UEFS Foto: Patrícia Brito.

A referida documentação foi editada por Brito (2020), conforme critérios de transcrição de textos manuscritos do Programa para a História do Português Brasileiro 


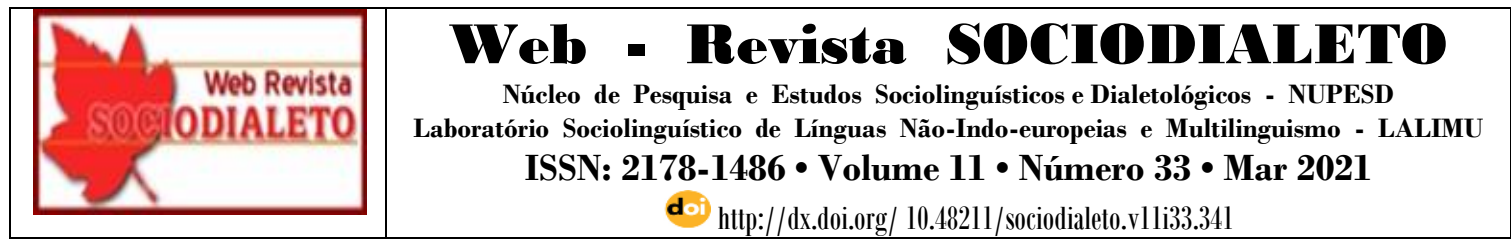

$(\mathrm{PHPB})^{5}$ e está disponível nas plataformas http://www5.uefs.br/cedohs/ e http://www5.uefs.br/cedohs/cartasmarienses/.

As correspondências podem ser consideradas de circulação privada nos termos evidenciados por Barbosa (1999) ${ }^{6}$. Em se tratando de documentos escritos em sincronias passadas, segundo o autor, essa tipologia textual é a preferida dos pesquisadores em Linguística Histórica, pois "é o que mais se aproxima de uma escrita cotidiana, aquela que tem maior chance de alcançar o limite possível de transparência na escrita de dados da oralidade, ocorrências de formas novas em difusão na sociedade" (BARBOSA, 1999, p. 147).

As cartas são de caráter afetivo, foram enviadas com a finalidade de expressar saudades, obter e dar notícias, desejar votos de felicitações, fazer pedidos, entre outros. São produtos gráficos que apresentam especial relevância para os estudos que abrangem as vertentes populares do $\mathrm{PB}$, pois representa uma escrita cotidiana, menos monitorada de pessoas pouco escolarizadas, de épocas pretéritas. Sabe-se que o fenômeno em estudo é um dos mais investigados no âmbito da sociolinguística variacionista, no entanto esses estudos se apoiam em corpora orais em uma sincronia contemporânea, a exemplo de Scherre (1988), Naro (1981) e Lopes (2001). O trabalho em questão vem suprir uma lacuna de trabalhos nessa perspectiva por se tratar de corpora escritos em sincronias passadas.

\section{PRESSUPOSTOS TEÓRICO E METODOLÓGICO}

Este trabalho se insere no âmbito da Linguística Histórica sócio histórica no seu sentido stricto, nos termos postulados por (WEINREICH, LABOV E HERZOG [1972] 2006), para os quais a mudança linguística deve ser explicada considerando não só os

\footnotetext{
5 Conferir normas de transcrição no site: https://sites.google.com/site/corporaphpb/home/normas-deedicao-do-phpb-2a-versao

${ }^{6}$ Segundo Barbosa (1999), os documentos de circulação oficial inclui os documentos da administração pública e os documentos de circulação privada incluem os documentos da administração privada e os particulares.
} 
condicionantes linguísticos, mas também os condicionantes sociais. E também no seu sentido lato definido por Mattos e Silva (2008), por trabalhar com corpus datado e localizado.

No presente trabalho, fazemos uma análise da concordância gramatical de número plural, entre os elementos flexionáveis do sintagma nominal, no $\mathrm{PB}$, em textos escritos, ao longo do século XX, no interior baiano. Tal análise foi feita sob duas perspectivas: a atomística (ou mórfica), que considera cada elemento do SN como um dado de análise e não atomística (ou sintagmática), que considera o SN inteiro como unidade de análise.

A análise aqui proposta caminhou por uma trilha descritivo-interpretativista. No entanto, não se utilizou dos subsídios do programa Goldvarb X com todo o seu refinamento, em vista dos poucos dados encontrados e por estarem enviesados em algumas circunstâncias. Os dados obtidos foram discutidos por meio de resultados percentuais.

Fixamos como variável dependente a realização ou não da marca de concordância nominal de número. Como variáveis independentes fixaram-se as variáveis linguísticas e sociais. Como os dados não foram rodados no programa estatístico Goldvarb X, aventam-se algumas variáveis consideradas relevantes para os estudos precedentes: A seguir (Quadro 1) com a relação das variáveis independentes analisadas:

Quadro 1: Variáveis independentes linguísticas e sociais.

\begin{tabular}{|c|c|c|}
\hline & Linguísticas & Sociais \\
\hline \multirow{3}{*}{ 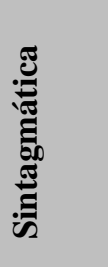 } & Posição do SN com relação ao verbo & Situação de aprendizagem \\
\hline & Número absoluto de constituintes do SN & Presença/ausência em fórmulas \\
\hline & - & Gênero \\
\hline$\stackrel{\ominus}{\gtrless}$ & Posição do constituinte em relação ao verbo & Situação de aprendizagem \\
\hline
\end{tabular}




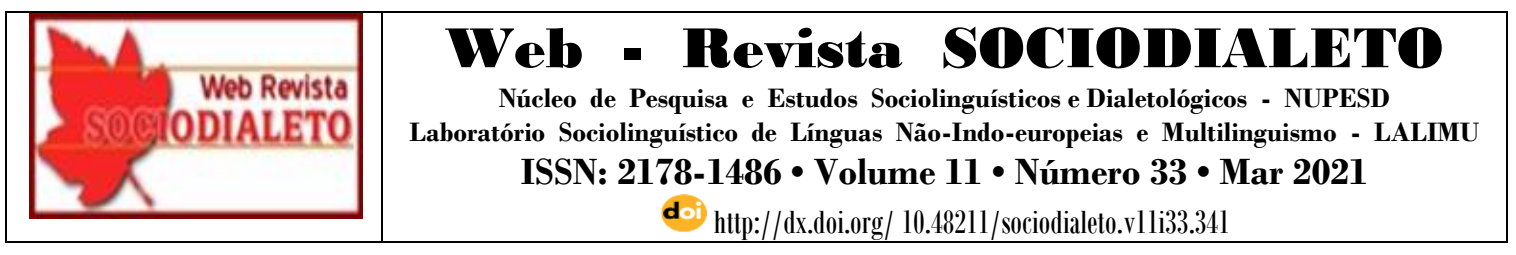

\begin{tabular}{|l|l|l|}
\hline Saliência fônica e Tonicidade & Presença/ausência em fórmulas \\
\cline { 2 - 3 } & Marcas precedentes ao item analisado & Gênero \\
\hline
\end{tabular}

Fonte: elaborado pela autora.

A análise contemplou todo e qualquer $\mathrm{SN}$ que tinha pelo menos uma marca formal ou semântica de plural que implicasse na marcação de outros elementos flexionáveis do SN posteriores. Assim, dados que a tradição gramatical prevê como marcação explícita ou implícita de plural, mas que não estejam marcados, e por isso, considere como erro foi objeto dessa análise. O valor positivo foi atribuído aos SNs cujos constituintes são todos marcados, como mostram os exemplos a seguir:

(i) SNs com todas as marcas formais de plural

1. [...] sempre dizia para as minhas amigas antes quero [...] (MJPS, C-14)

(ii) SNs com algumas marcas formais de plural

2. Abraço em Valter e as minhas netinhaØ (MJPS, C-50)

(iii) SNs com apenas uma marca formal de plural ou até sem nenhuma marca formal explícita, quando ocorre um SN contendo um numeral como primeiro elemento seguido de outros elementos não marcados

3. [...]vê e não ouvir mas êstes | bilhetinhoØ enjoadoØ? [...](MJPS, C-31)

4. Eu lhe dezejo mil vezØ tudo aquilo que você me[...] (MZNM, C-69)

Estabelecido os caminhos da pesquisa, foi feito um levantamento exaustivo das ocorrências que serviram de base para a análise.

5 ANÁLISE DOS DADOS

5.1 PERSPECTIVA SINTAGMÁTICA 
Na perspectiva sintagmática ou não atomística toma-se como base de análise o SN por inteiro. Consideramos como dados de análise a presença de marca de pluralidade em todos os elementos passíveis de flexão do $\mathrm{SN}$, ou seja, como aplicação da regra, exemplificado em (01) versus ausência de marca de pluralidade em pelo menos um dos elementos do SN passíveis de receber a marcação, ou seja, como não aplicação da regra, exemplificado em (02).

(01) a. Em todas as novenas teve ro-|maria. (JPS, C -10)

(02) b. [...] - | a outra abandonou os ovos |cheioØ, perdeu (MJPS, C-19)

Das Cartas Marienses extraíram-se 338 sintagmas nominais, passíveis de receber a marca de concordância nominal de número. Destes, $262(77,5 \%)$ obtiveram a marca de plural, enquanto que os demais, $76(22,5 \%)$ não foram marcados, como se observa na tabela a seguir:

Tabela1: Variação da concordância no SN.

\begin{tabular}{c|c|c}
\hline $\begin{array}{c}\text { SINTAGMA } \\
\text { NOMINAL }\end{array}$ & Frequência & $\%$ \\
\hline Com concordância & $262 / 337$ & 77,5 \\
\hline Sem concordância & $76 / 337$ & 22,5 \\
\hline
\end{tabular}

Fonte: Elaborado pela autora.

Os dados revelam altos índices de marcação de pluralidade, o que a primeira vista é surpreendente, especialmente por se tratar de textos informais, escritos por indivíduos com pouca escolaridade. Analisaremos a seguir as variáveis independentes linguísticas e sociais aventadas. 


\subsubsection{Variáveis linguísticas}

Buscando traçar um perfil da variação da concordância nominal de número no corpus, selecionamos dois grupos de fatores linguísticos, a saber: (i) a posição do $S N$ em relação ao verbo e (ii) o número absoluto de constituintes do SN. Pesquisas anteriores no âmbito da sociolinguística variacionista que tratam do fenômeno investigado: Scherre (1988), Lopes (2001), Santos (2017) consideram essas variáveis importantes para a marcação ou não da marca formal de concordância.

\subsubsection{Posição do SN com relação ao verbo}

O estudo dessa variável tem o objetivo de entender a influência da configuração sintagmática do SN. De acordo com Scherre (1997), subjacente a esta variável encontrase a hipótese de que os SNs à esquerda da oração, numa posição de tópico ${ }^{7}$, tenderiam a se apresentar com todas as variantes explícitas. Lemle e Naro (1977) e Naro (1981) demostraram que a presença do sujeito e a sua posição em relação ao verbo têm forte influência no tipo de variante nas formas verbais.

Este trabalho assume a hipótese de que a posição do SN em relação ao verbo interfere na marcação. Sintagmas nominais à esquerda do verbo tendem a ser mais marcados que àqueles situados na posição direita. Como em alguns casos não há uma nitidez com relação à posição analisa-se esta variável considerando três fatores: posição à esquerda, posição à direita e posição isolada. Estas ocorrências podem ser verificadas nos exemplos a seguir:

(i) Posição à esquerda

a) [...] você |e suas companheiras passam [...]. (MJPS, C-33)

b) os exameØ foi discuberto o mal, foi o problema da [...]. (HÁ, C-83)

\footnotetext{
${ }^{7}$ ( Cf. Pontes, 1986; e Naro \& Votre, 1986)
} 


\begin{tabular}{|c|c|}
\hline $\begin{array}{l}\text { Web Revista } \\
\text { ODIALET0 }\end{array}$ & 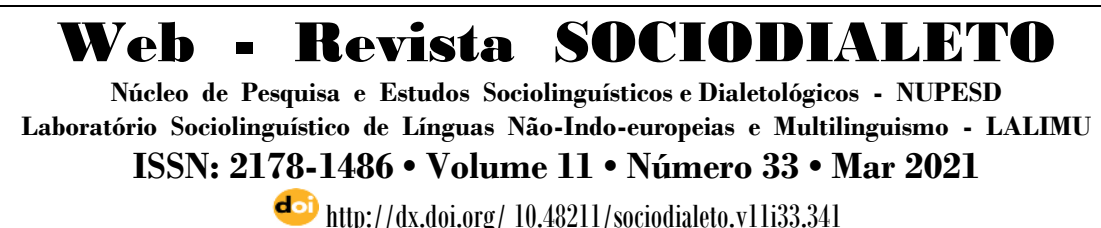 \\
\hline
\end{tabular}

\section{(ii) Posição à direita}

a) Recebi suas cartas (quase uma dentro da outra) [...]

\section{(iii) Posição isolada}

a) Minhas filhas (MJPS, C-21)

b) Aos meus filhoØ (MJPS,C-25)

Gráfico 1: Efeito da posição do SN em relação ao verbo na variação da concordância.

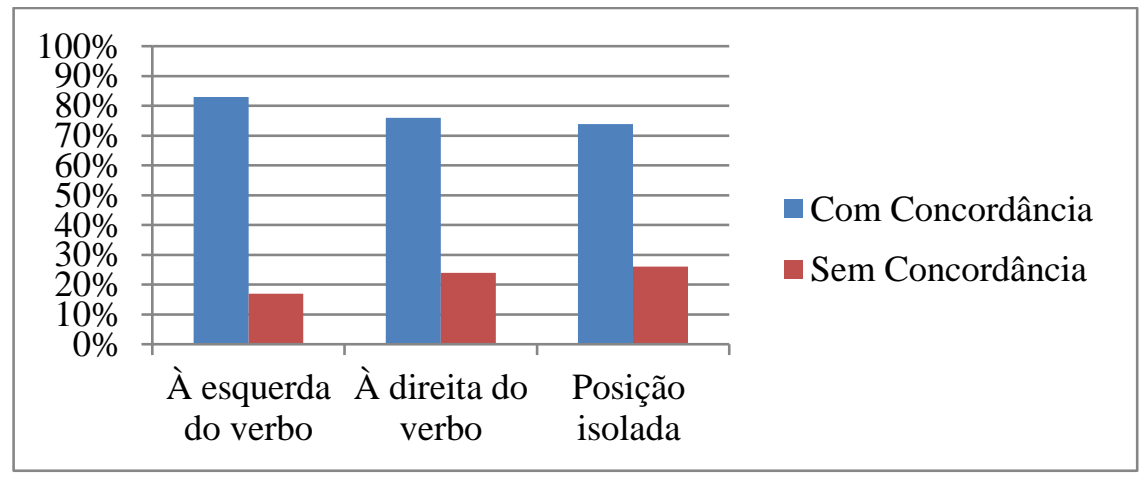

Fonte: Elaborado pela autora.

Os dados mostram que, os SNs localizados à esquerda do verbo apresentam maior favorecimento à marcação de pluralidade entre os elementos flexionáveis do SN, com 83,3 pontos percentuais. Situação similar aconteceu com os SNs localizados à direita do verbo, com uma média percentual de $76 \%$, seguido da posição isolada que figurou como a que menos favoreceu a marcação canônica, com uma média de $73.9 \%$.

A análise dos dados mostrou que a posição dos SNs em relação ao verbo interferiu na marcação. Assim, confirma-se a hipótese de que nas Cartas Marienses, a posição do SN em relação ao verbo exerce influência na marcação de pluralidade e que os sintagmas à esquerda do verbo tendem a favorecer mais à aplicação da regra canônica de concordância nominal de número de que os SNs localizados à direta do verbo e em posição isolada. 


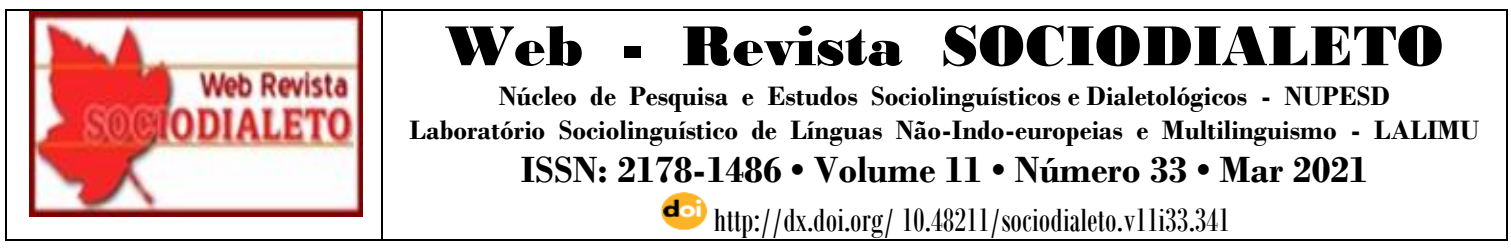

\subsubsection{Número absoluto de constituintes}

A análise da variável número absoluto de constituintes tem o intuito de verificar se a extensão sintagmática, composta pelos constituintes totais interfere na marcação ou não da regra formal de concordância. Neste estudo, repartimos a variável em três fatores: sintagmas compostos por dois constituintes; sintagmas compostos por três constituintes; e aqueles formados por quatro ou mais constituintes. As construções a seguir exemplificam estes fatores:

(i) Compostos por 2 constituintes

a) Eu tenho guardadas as poesias (JPS, C-7)

b) [...] se Clóvis que pega as almofada $\emptyset$ e deixou por ai. .( MJPS, C-1

(ii) Compostos por 3 constituintes

a) $[\ldots]$ contente todas as vezes $\mid$ que recebia algumas [...](MJPS, C -23)

b) Que Jesus lhe ilumine todos seus |caminhoØ (MNM, C-80)

(iii) Compostos por 4 constituintes

a) [...] | ótima, marido responsável, os meus filhos |ótimos. (MJPS, C-19)

b) A paz de Deus esteja com você e minha ne-| tinha e todas aØ suas amigas pois que são minhas também (MJPS, C-48

No gráfico a seguir, expõem-se os dados obtidos nas Cartas Marienses:

Gráfico 2- Efeito do número absoluto de constituintes do SN na variação da concordância de número.

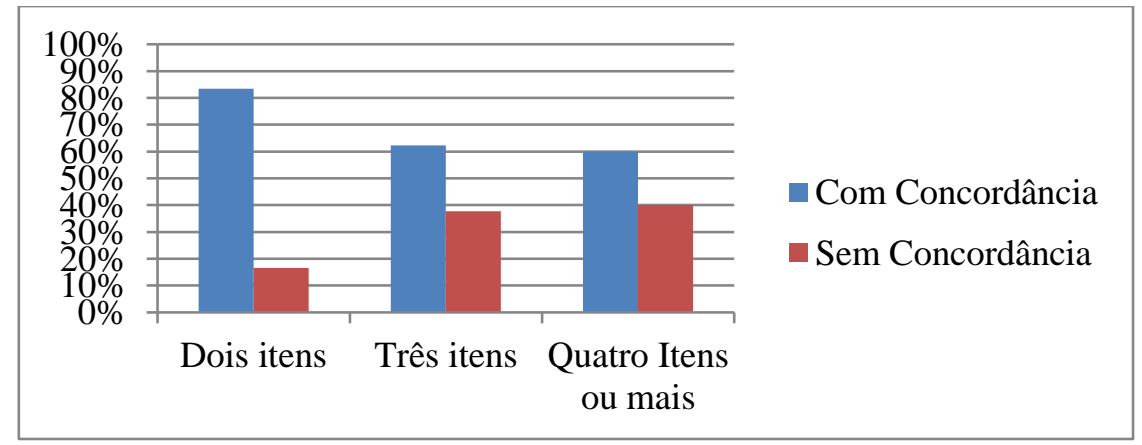

Fonte: Elaborado pela autora. 
Conforme se observa nos dados do gráfico, os sintagmas compostos por dois itens foram os que mais favoreceram a marcação de pluralidade com 83 . 4\% pontos percentuais. Já os SNs compostos por três itens ou aqueles formados por quatro itens ou mais, apesar de apresentarem índices altos de marcação formal, 62,3 \% e 60\%, respectivamente, tendem a desfavorecer a aplicação da regra de concordância no corpus analisado.

Nesse sentido, pode-se observar que os SNs compostos por dois itens tendem a ser mais marcados que aqueles que possuem três itens ou mais. Os dados indicam que os SNs que apresentam maior extensão apresentam tendência a não marcação, ao contrário daqueles que possuem extensão menor, que apresentam maiores índices de marcação.

\subsubsection{Variáveis sociais}

A análise das variáveis sociais tem se mostrado de grande valia para os estudos das mudanças linguísticas. Principalmente, em se tratando do fenômeno da variação da concordância de número no $\mathrm{SN}$, que figura como um dos aspectos variáveis mais estigmatizados socialmente. Diversos estudos, no âmbito da sociolinguística variacionista, têm demostrado que a não aplicação da regra de concordância tem motivações linguísticas e sociais. Nesse sentido, como bem colocam WEINREICH; LABOV; HERZOG, [2006] 1968, a mudança deve ser explicada não somente por argumentos internos ao sistema, mas também pelos externos.

As variáveis sociais selecionadas para a análise dos dados foram: situação de aprendizagem; presença/ausência do constituinte em fórmulas, e sexo. Essas variáveis têm sido relevantes para o estudo de corpora com características semelhantes.

\subsubsection{Situação de aprendizagem}

Nos estudos sociolinguísticos uma das variáveis consideradas mais importantes no que se refere às variáveis sociais é o nível de escolaridade do informante. Estudos 


\begin{tabular}{|c|c|}
\hline $\begin{array}{r}\text { Web Revista } \\
\text { ODIALETO }\end{array}$ & 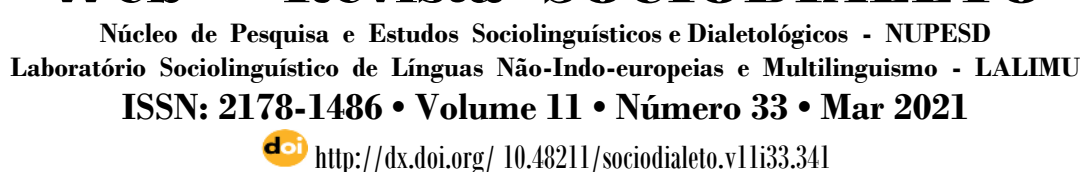 \\
\hline
\end{tabular}

precedentes $^{8}$ mostram que indivíduos com nível de escolaridade maior tendem a concretizar mais as marcas formais de concordância que àqueles com pouco nível de escolaridade. Sobre este aspecto, Lopes (2001, p. 381) afirma que a escolarização "é um dos grupos de fatores de forte efeito na concordância". Quanto maior for o nível de escolaridade, maior será o nível de concordância.

O termo situação de aprendizagem foi utilizado considerando as particularidades de aprendizado de cada remetente das Cartas Marienses. Para avaliar o efeito desta variável, no corpus desmembrou-a em quatro situações: aqueles que aprenderam a ler e escrever em ambientes extraescolares; aqueles que estudaram apenas os primeiros anos (primário); aqueles que estudaram até a $8^{a}$ série (Fundamental II) e; aqueles que concluíram o ensino médio.

O gráfico, a seguir, exibe os resultados encontrados:

Gráfico 3: Efeito da situação de aprendizagem na variação da concordância de número nos SNs.

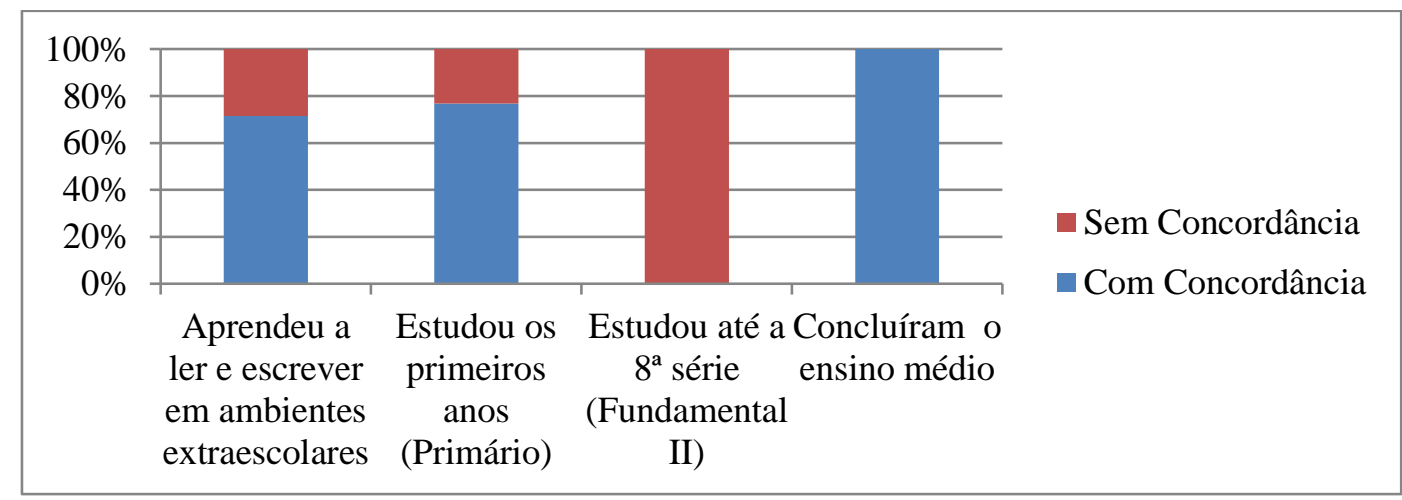

Fonte: Elaborado pela autora.

Os dados obtidos trazem resultados surpreendentes, uma vez que exibem marcas categóricas tanto para a marcação de pluralidade quanto para a não marcação. Das situações analisadas, aquela que favoreceu categoricamente as marcas explícitas de plural foi aquela em que os remetentes concluíram o ensino médio, com $100 \%$ de pontos percentuais. Em seguida, aqueles remetentes que estudaram os primeiros

\footnotetext{
${ }^{8}$ Lopes (2001)
} 
anos/formação primária que obtiveram a marca de $76.8 \%$ de marcação. Os remetentes que aprenderam a ler e escrever em ambientes extraescolares obedeceram as marcas formais em uma média de $71.4 \%$. Já àqueles remetentes que estudaram até a $8^{\mathrm{a}}$ série, desfavoreceu de forma categórica, chegando a $100 \%$ de ausência de marcas explícitas de plural nos SNs. Esses dados enviesam, em certa medida, os resultados, uma vez que se tratam de apenas $5 \mathrm{SNs}$, escritos por 2 remetentes.

A falta de marcas formais nos SNs produzidos pelos remetentes que estudaram até a $8^{\mathrm{a}}$ série merece atenção, já que apresentou um índice de marcação inferior àqueles que possuem nível de escolaridade menor. Somado aos poucos dados dessa variável, uma hipótese a se considerar em relação à ausência de marcas é o fato desses indivíduos terem tido um aprendizado insuficiente, resultado de um processo de ensino irregular e precário.

Conclui-se, portanto que o nível de escolaridade exerce influência na exibição de marcas formais, assim como mostrou Lopes (2001), e que a qualidade do ensinoaprendizado contribui para o desempenho.

\subsubsection{Presença/ ausência do constituinte em fórmulas}

A análise dessa variável tem o intuito de avaliar se as expressões formulaicas presentes nessa tipologia textual influenciam a marcação ou não da concordância, pois por mais que esse tipo de texto se atualize no tempo e no espaço, determinadas características permanecem, como cabeçalho, data, localização, assinatura, expressões formulaicas, o enunciado introdutório e ou finalizador, que já estão cristalizados na sociedade.

Dos 337 sintagmas que compõe o corpus, 26 (7.7\%) residem em fórmulas, enquanto que os demais 311 (92.2), residem fora das expressões formulaicas.

\section{Sintagmas presentes nas fórmulas com a marcação de pluralidade}

a) Envio-te estas duas Linhas para | saber das tuas noticías [...] (Z, C-54) 


\begin{tabular}{|c|c|}
\hline $\begin{array}{l}\text { Web Revista } \\
\text { ODIALETO }\end{array}$ & $\begin{array}{c}\text { Núcleo de Pesquisa e Estudos Sociolinguísticos e Dialetológicos - NUPESD } \\
\text { Laboratório Sociolinguístico de Línguas Não-Indo-europeias e Multilinguismo - LALIMU } \\
\text { ISSN: 2178-1486 • Volume } 11 \bullet \text { Número 33 } \text { Mar 2021 } \\
\text { d } 11 \text { http://dx.doi.org/ } 10.48211 / \text { sociodialeto.vlli33.34l }\end{array}$ \\
\hline
\end{tabular}

b) São $\mathbf{O S}$ voto $\underline{\mathbf{S}}$ Sincero $\underline{\mathbf{S}}$ de Sua amiga Nilza que tanto lhe [...] (N, C- 88

2. Sintagmas presentes nas fórmulas sem a marcação de pluralidade

a) [...] fim desta | e para dar as minhaØ noticiaØ i ao [...] (EMO, C-58)

b) Eses são meus sinceroØ votoØ da sua subrinha [...] (MNM*, C-73

3. Sintagmas fora das fórmulas com a marcação de pluralidade

a) Lindalva que já é tempo dos Sagués deixar[...](MJPS, C-31)

b) Vou finalizando levo muitas Saudades $\mid$ de você (HA, C-83)

4. Sintagmas fora das fórmulas sem a marcação de pluralidade

a) [...] esta fasendo as refésãoØ aqui eu |não sei se te [...](MNPS, C-12)

b) [...] a outra abandonou os ovos $\mid$ cheioØ, perdeu (MJPS, C-19)

Gráfico 4 : Efeito da presença/ausência em fórmulas na variação da concordância de número nos SNs.

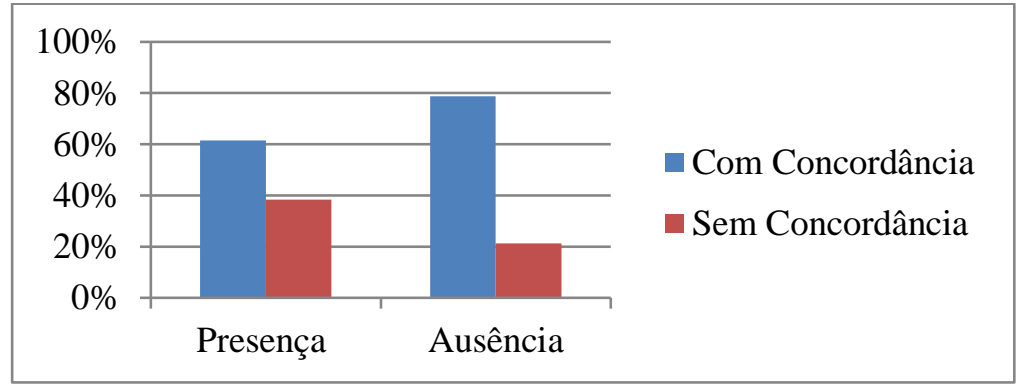

Fonte: Elaborado pela autora.

Os dados mostram que dos 26 sintagmas que residem em fórmulas, 10 (38.4\%) não receberam a marca formal de pluralidade, enquanto que os demais, 16 (61.5\%) foram marcados. Analisou-se também como se deu o efeito da concordância nos sintagmas nominais fora das fórmulas. Os dados dizem o seguinte: 311 sintagmas residem fora de fórmulas, dos quais $78.7 \%$ foram marcados formalmente, enquanto que o restante, 66 (21.2\%) não apresentam marcas de pluralidade. 
O que se observa em se tratando dos sintagmas nominais presentes nas fórmulas é que a maior parte, $61.5 \%$ apresenta marcação de pluralidade. Nota-se com esses resultados que estas construções não são um espaço de resistências às variações, como outrora revelaram Oliveira, Souza e Coelho (2009) e Santos (2017).

\subsubsection{Gênero}

No quadro da teoria sociolinguística variacionista, a variável sexo figura como uma das principais entre as variáveis sociais. Para Labov (2008 [1972]), a distinção sexual exerce um caráter relevante quando se trata de análise da variação e mudança linguística. De acordo com, o autor, “[...] as mulheres usam as formas mais avançadas em sua própria fala informal e se corrigem mais nitidamente no outro extremo da fala monitorada." (LABOV, 2008 [1972], p. 346). Diante dessa evidência, busca-se analisar o efeito dessa variável no corpus repartindo-a em dois fatores: feminino e masculino.

As construções, a seguir, exemplificam tais fatores:

\section{Feminino}

a) $[\ldots]$ emmen-|dando, as pernas que não aguento [...](MNPS, C-12)

b) $[. .$.$] pronta sí não for nas festaØ vai Depois [...] (MNM, C- 71)$

\section{Masculino}

a) [...] disculpi os | erros ... nada mais do seu querido irmão [...] (EMO, C-58

b) [...] que reci-|bir das tuas delicadaØ mãoØ | que a aceite [...] (JMO, C-56 


\begin{tabular}{|c|c|}
\hline $\begin{array}{l}\text { Web Revista } \\
\text { ODIALETO }\end{array}$ & $\begin{array}{c}\text { Núcleo de Pesquisa e Estudos Sociolinguísticos e Dialetológicos - NUPESD } \\
\text { Laboratório Sociolinguístico de Línguas Não-Indo-europeias e Multilinguismo - LALIMU } \\
\text { ISSN: 2178-1486 • Volume } 11 \bullet \text { Número 33 } \text { Mar 2021 } \\
\text { d } 11 \text { http://dx.doi.org/ } 10.48211 / \text { sociodialeto.vlli33.34l }\end{array}$ \\
\hline
\end{tabular}

Gráfico 5: Efeito do Gênero sobre a variação da concordância nominal de número, nas Cartas Marienses.

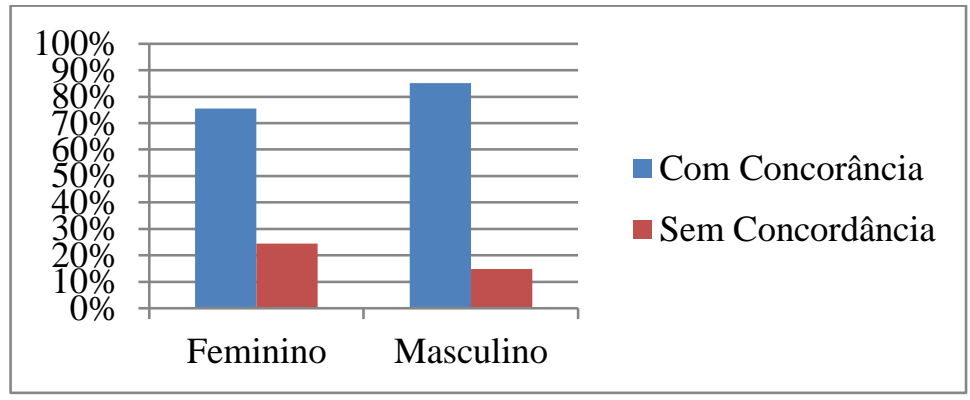

Fonte: Elaborado pela autora.

Os resultados mostram que os homens concretizam as marcas formais em $85.1 \%$, enquanto que as mulheres exibem 75.6\%. Assim, os homens favorecem mais a marcação de plural que as mulheres. Esses dados podem estar relacionados ao contexto social em que os homens eram expostos, como, por exemplo: estada fora da comunidade, considerando àqueles redatores que no momento da escrita das cartas se encontravam em outra cidade, em busca de melhores condições de vida.

\subsection{PERSPECTIVA ATOMÍSTICA}

Nessa perspectiva, toma-se como base de análise cada um dos constituintes passíveis de receber a flexão de número nos SNs. Desse modo, todo constituinte formalmente marcado considera-se presença de concordância; aqueles que não estiverem marcados formalmente consideram-se ausência de concordância. Como mostram os exemplos:

(i) Constituinte marcado

a) Alô minhas filhas e familia | Espero que estejam [...].( MJPS, C-18)

(ii) Constituinte não marcado

a) [...] mas nas hora $\varnothing \mid$ da tresteza com vesse com seu [...] (ISL, C-62) 
Das Cartas Marienses retiraram-se um total, de 773 constituintes, passíveis de receber a concordância de número no SN. Destes, $683(88.4 \%)$ receberam a marca de concordância, enquanto $90(11,64)$ não receberam a marca. O gráfico, a seguir, exibe os dados:

Gráfico 6: Variação da Concordância entre os constituintes dos SNs nas Cartas Marienses.

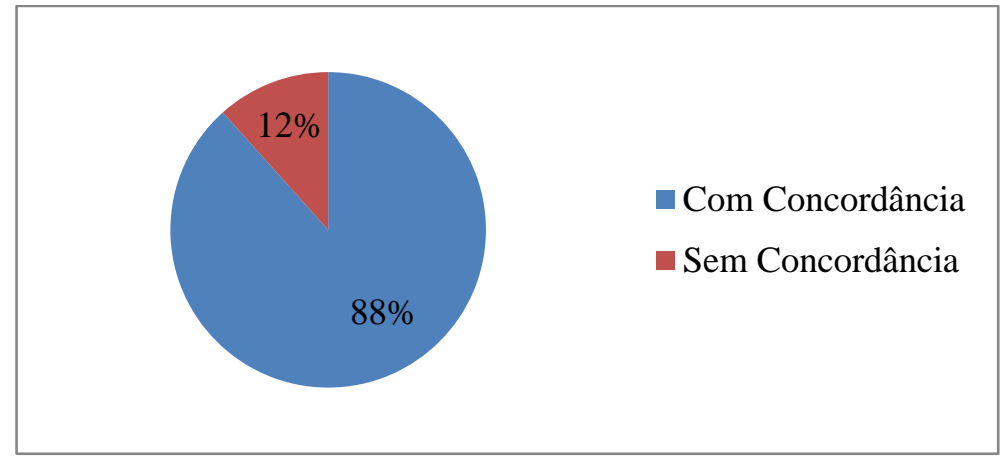

Fonte: Elaborado pela autora.

\subsubsection{Variáveis linguísticas}

Com o objetivo de trazer uma visão clara de como a variação da concordância nominal de número ocorre nos constituintes do $\mathrm{SN}$, faz-se uma análise nos seguintes grupos de fatores linguísticos: (i) a posição do constituinte em relação ao núcleo; (ii) a saliência fônica envolvendo a tonicidade; e (iii) marcas precedentes ao elemento analisado. Essas variáveis foram selecionadas por terem sido consideradas relevantes para a exibição ou não da marca de pluralidade nos Constituintes do SNs, em estudos precedentes ${ }^{9}$.

\footnotetext{
${ }^{9}$ Scherre (1988); Lopes (2001); Baxter (2006), entre outros.
} 


\subsubsection{Posição do constituinte em relação ao núcleo}

A análise da posição do constituinte em relação ao núcleo estuda o funcionamento da concordância nominal em relação ao posicionamento dos elementos não nucleares em relação ao elemento nuclear: se anterior ao núcleo na posição esquerda, se anterior ao núcleo à esquerda, mas não próximo, se nuclear ou se à direita do núcleo.

Ao observar essa variável Scherre $(1988,1998)$ analisando-a conjuntamente com a variável posição e a variável categoria morfológica, concluiu que as classes antepostas ao núcleo tendem a ser mais marcadas do que as pospostas a ele. No entanto, sem fazer uma distinção entre as classes adjacentes e não adjacentes ao núcleo; e as classes mais próximas ao núcleo em primeira e em segunda posição.

Lopes (2001) adotou o mesmo procedimento de Scherre (1988), na análise da fala de Salvador. A autora concluiu que os elementos não nucleares a esquerda do núcleo são mais marcados que aqueles posicionados à direita e que a adjacência ao núcleo dos elementos à esquerda dele é um forte condicionador de mais marcas.

Neste trabalho, configurou-se a posição do constituinte em relação ao verbo seguindo o modelo de Scherre (1988, 1998), no entanto fazendo uma distinção em relação às posições pré- nucleares em termos de proximidade do núcleo. Em relação a variável posição e a categoria morfológica analisamos conjuntamente por acreditar que essa variável já inclui os elementos nucleares (substantivos e categorias substantivadas) e os elementos não nucleares (artigos, adjetivos, demonstrativos, e outros).

A variável foi desmembrada em seis categorias: à esquerda adjacente ao núcleo, à esquerda não adjacente ao núcleo, núcleo em $1^{a}$ posição, núcleo em $2^{a}$ posição , núcleo em $3^{a}$ posição em diante, itens à direita do núcleo ${ }^{10}$. Colocam-se abaixo exemplos de ocorrências que representam essas categorias.

\footnotetext{
${ }^{10}$ Considerou-se nessa análise, apenas a linearidade do constituinte em relação ao núcleo.
} 


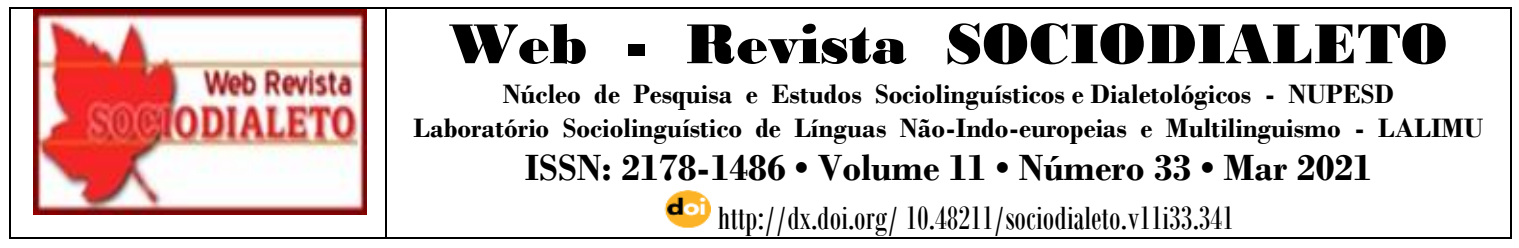

(i) À esquerda adjacente ao núcleo

a) Com referensa a seos fumos, peço favor de chegar [...].(M, C-3)

b) [...] via aqui passa umØ dias e ater hoje | eu espero. (MNM, C-80)

(ii) À esquerda não adjacente ao núcleo

a) Eses são meus sincero voto da sua subrinha [...] (MNM, C-73

b) [...] lhe escrevo esta $\emptyset$ duas linha (AOS, C-60)

(iii) Núcleo em $1^{\mathrm{a}}$ posição

a) [...] Quando quizer saber notícias nossa pode telefonar [...]MJPS, C-38

b) $[\ldots]$ poder ter o prazer de ter PerolaØ | Esparsas em meu [...] (MJPS, C-48)

(iv) Núcleo em $2^{\text {a }}$ posição

a) [...] ésta ao chegar em vossas |maõs, vão encontá, a to-[...] (JMO, C-55

b) $[\ldots] \mid$ vem todos os dias faz as rumaçãoØ pelo $\mid$ manhã [...](MNPS, C-12)

(v) Núcleo em $3^{\circ}$ posição em diante

a) $[\ldots ..] \mathrm{e}$ "carne"e os baixos pre-|ços de antes [...]. (JPS, C-8)

b) [...] nois Vencer todas as DeficolidadeØ_que [...] (MNM, C-79)

(vi) Itens à direita do núcleo

a) [...] e para sempre as bênçãos divinas coroem|...|| os [...] (MNM, C- 74)

b) [...] vamos respeitar, porque |somos os único culpadoØ. (AMO, C-64) 
Gráfico 7: Efeito da variável posição do constituinte em relação ao núcleo.

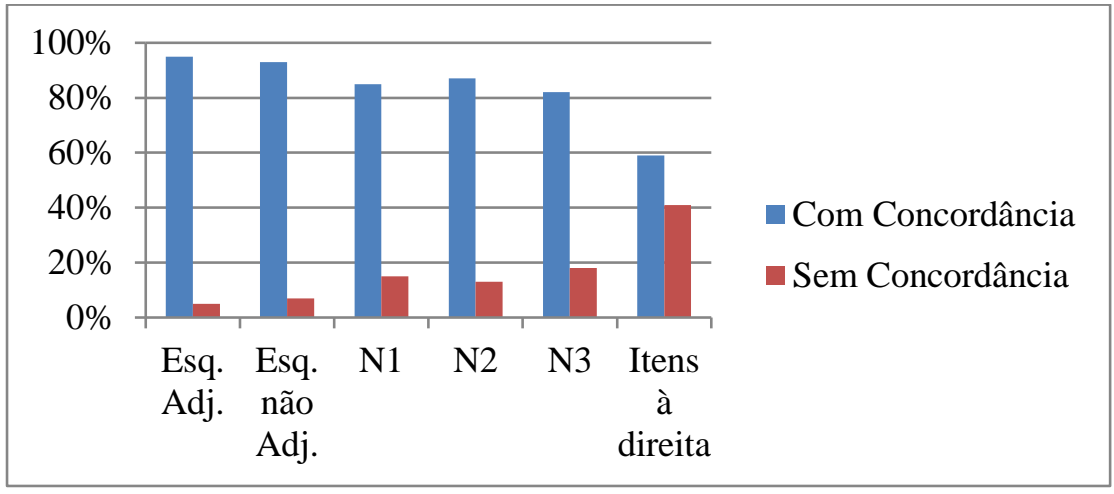

Fonte: Elaborado pela autora.

Os dados mostram que a posição à esquerda adjacente ao núcleo é a que mais favorece as marcas explícitas de plural com 95.5\%. Esse resultado evidencia uma marca semicategórica de marcação de pluralidade. A posição à esquerda não adjacente ao núcleo também exibe alto índice de marcação com 93.2\%. Os itens nucleares em $1^{\mathrm{a}}, 2$ ,e $3^{\mathrm{a}}$ posição exibem, respectivamente, 84.6, 87.5, 81.8, também, índices altos de marcação, porém favorecem menos que as posições à esquerda e à esquerda adjacentes ao núcleo. Já aposição à direita do núcleo foi a que apresentou maior desfavorecimento à marca formal de plural com $58.8 \%$ em relação aos demais itens.

Os resultados obtidos apontam para uma característica recorrente nos estudos que se debruçam a estudar a variação da concordância nominal, que é a tendência à marcação de pluralidade nos itens localizados em posições pré-nucleares, enquanto que os itens pós-nucleares exibem uma tendência a não marcação.

Um dado importante a se observar no corpus em estudo é o fato de alguns sintagmas apresentarem os determinantes sem marcação de pluralidade na primeira posição. Esse fenômeno foi constatado primeiramente por Scherre (1988), que ao explicá-lo argumenta que "os determinantes não marcados se encontram inseridos numa estrutura sintagmática bastante peculiar, ou seja, ocorrem nas sequências do tipo [artigo ou demonstrativo + possessivo+ substantivo]". Segundo a autora, essas ocorrências podem estar relacionadas ao fato de que os falantes poderiam estar analisando a 
contração do tipo no e po e como uma preposição, desse modo, uma categoria que não se flexiona e não apresenta marcas de plural. Scherre (1988) afirma ainda que, essa possibilidade de reanálise pode se estender aos artigos diante de possessivos precedidos de preposição, já que não apresenta contração e mesmo em contextos em que não são precedidos de preposição.

Situação semelhante foi encontrada por Lopes (2001), que observou a ocorrência desse fenômeno na fala de Salvador, na qual, também havia possessivos em quinze das dezenove situações. A autora, também verificou que os elementos mais distantes do elemento nuclear não foram marcados, o que a levou a supor que poderia ter alguma relação entre a ausência de marca e a estrutura com possessivos, mas que tudo indicava que não era o único elemento favorecedor.

Santos (2017), ao observar esse fenômeno nas cartas de inábeis percebeu que não era apenas em estruturas com possesivos que se notavam ausência de marcas na primeira posição. Segundo a autora, foram encontradas estruturas com numeral e adjetivo. A autora acredita que a estrutura sintagmática formada por um possessivo subsequente, por si só, não explica a ausência de marcas.

Nas Cartas Marienses foram encontrados 16 ocorrências que caracterizam esse fenômeno. Contudo, a ausência de marcação de plural na primeira posição não se encontra em uma estrutura peculiar, mas em estruturas diversas, como também observou Oliveira, Souza e Coelho (2009), nas atas dos africanos. A seguir os dados encontrados nesta pesquisa:

Estruturas em que não se marcou o plural na $1^{a}$ posição do sintagma:

[SUBST + ART + SUBST]: [...] mas toda $\emptyset$ as |vezes que me [...] (MJPS,C-25)

[PREP+ART+ADJ+SUBS]: DoØ velhos paes Antonio e Maria (MJPS, C-42)

[DEMOS+ NUM+ SUBST]: [...] lhe escrevo esta $\emptyset$ duas linha (AOS, C-60)

[PREP+ ART+POSS+SUBST]: [...]Seja |Feliz noØ seus estudo. (JCRB, C- 84)

[ART+SUBST]: $[\ldots]$ vem passar umØ dias com migo $[\ldots]^{11}$ (MNM, C-80)

[ART+SUBST]: Uma Ø fatadas em jarde | todo mundo [...](MJPS,C-26)

[ADJ+SUBST]: [...] meus sinceros votos de boaØ festas e a no novo. (MZNM, C-68)

\footnotetext{
${ }^{11}$ Houve duas ocorrências com a mesma estrutura
} 
[PREP+ART+POSSE]: [...] saber daØ tuas | como vai voçes di [...] (MSJ, C-61)

[DEMOS+NUM+ADJ+SUBST]: [...] que estaØ duas | mal traçada [...] (AOS, C-60)

[IND+SUBST]: [...] namorados dizia | algumaØ pessoas (MJPS, C-51)

[ART+ADJ+SUBST]: Aceite um $\emptyset$ forte abraços dos seus velhos [...] (MJPS, C-49)

[PREP+ART+ART+SUBST]: Obrigada pela $\varnothing$ as importacia que [...] (MJPS, C-38)

[ADJ+SUBST]: ForteØ abraços para todos [...].( MJPS, C-18)

[DEMOS+NUM+SUBST]: [...] lhe escrevo esta $\emptyset$ duas linha (AOS, C-60)

[ART+NUM+PREP+ART+SUBST]: Em primêiro luga mando umø | Milhoes Dê Bença Mêus dois querido pais (E, C-89)

\subsubsection{Saliência fônica e tonicidade}

A variável Saliência fônica foi introduzida nos estudos sobre o PB em 1976, por Lemle e Naro. Desde então, tem sido considerada uma variável linguística importante para os estudos sobre a concordância. Segundo os autores, a quantidade de material fônico existente na oposição singular/plural interfere no que diz respeito à realização ou não da concordância. Formas linguísticas mais salientes tendem a concretizar a marca de pluralidade, enquanto que as formas menos salientes tendem a não marcar.

Scherre (1988) analisou a Saliência fônica considerando processos de formação de plural e tonicidade. Seus resultados mostraram que há mais variação nas formas em que há menos material fônico na oposição singular e plural.

Lopes (2001) analisou a saliência fônica, processos e tonicidade, como uma única variável. Suas conclusões mostraram que a variável saliência tem grande influência sobre a marcação ou não da concordância.

Neste trabalho, elaborou-se uma escala para análise da saliência fônica, na qual figuram o plural metafônico, palavras terminadas em $/ L /$, palavras terminadas em $/ R /$, palavras terminadas em /S/ ou /Z/, palavras terminadas em - ão regular, e palavras terminadas em - ão irregular, e palavras com marcação de plural regular em que só se acrescenta o s. Seguindo as orientações de Scherre (1988) e Lopes (2001), as variáveis processos de formação de plural e tonicidade serão analisadas de maneira geral, como a 


\begin{tabular}{|c|c|}
\hline $\begin{array}{r}\text { Web Revista } \\
\text { ODIALETO }\end{array}$ & 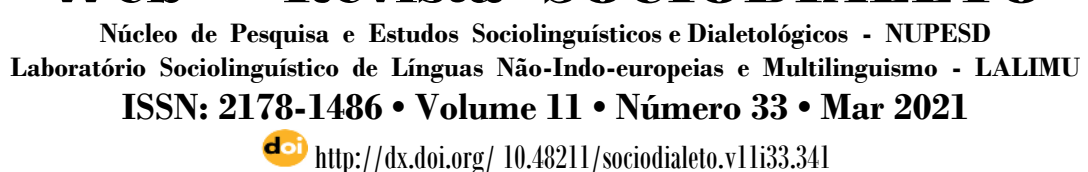 \\
\hline
\end{tabular}

saliência fônica. Assim, analisaremos de acordo com os seguintes fatores: a) Os SNs de plural regular, considerando a tonicidade: Regular oxítono ou monossílabo tônico; regular paroxítono, regular proparoxítono; b) processos de formação de plural: itens com plural metafônico ou duplo, itens terminados em $/ R /$, itens terminados em $/ L /$, itens terminados em /S/ ou/Z/, itens terminados em ão regular e itens terminados em ão irregular.

Neste trabalho, os monossílabos átonos não serão analisados, uma vez que em análises anteriores, Scherre (1988), e Lopes (2001), esses itens (artigos) estão sempre em posição única, a maioria, em primeira posição, o que explica a sua marcação de pluralidade, e não o fato de serem monossílabos. Desse modo, irrelevante para esta pesquisa.

Gráfico 8 : Efeito da Saliência fônica na concordância nominal.

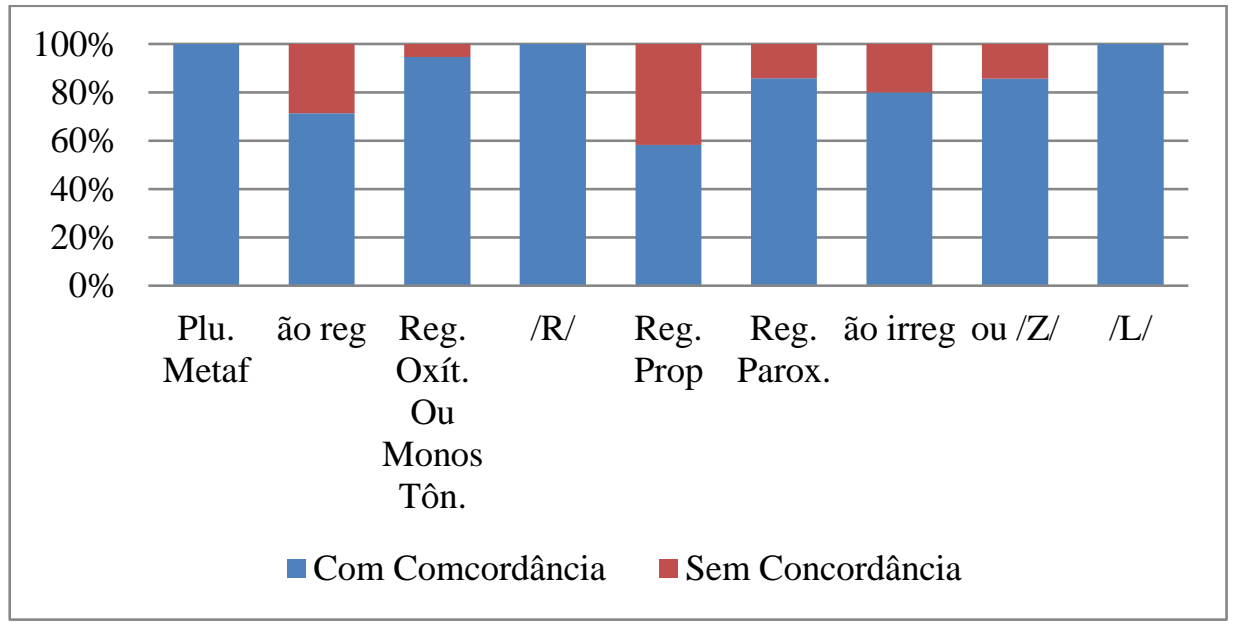

Fonte: Elaborado pela autora.

Os dados mostram que os vocábulos que apresentam maior porcentagem de concordância, mesmo considerando os poucos dados encontrados, foram os itens formados por plural metafônico, os itens terminados em /L/ e os itens terminados em /R/, exibiram marca categórica com uma porcentagem de 100\%. Também apresentaram altos índices de marcação os itens, regular oxítono ou monossílabos 
átonos, os itens terminados em /S/e /Z/ e regular paroxítono, com uma porcentagem e 94.7, 85.7 e 85.8 , respectivamente.

Os itens terminados em -ão irregular e -ão regular marcaram $80 \%$ e $71.4 \%$, respectivamente, mesmo desfavorecendo a marcação em relação aos outros itens mencionados. Dentre todos os itens analisados, aquele que se mostrou mais desfavorável à obtenção da marca de plural foi o item regular proparoxítono com 58.2 pontos percentuais.

Diante dos dados apresentados, observa-se que na escala da saliência fônica, na dimensão maior ou menor oposição de substância fônica entre as formas singular/plural, os itens com maior saliência fônica obtiveram maiores marcas explícitas de plural, que aqueles com menor saliência, sendo menos receptivos às marcas. Quanto aos itens relacionados aos processos e tonicidade, constata-se que os itens formados pelos oxítonos regulares e monossílabos tônicos exercem maior peso na probabilidade de obtenção da marca formal, que os paroxítonos e proparoxítonos, que são menos salientes, portanto menos marcados.

\subsubsection{Marcas precedentes ao elemento nominal}

Essa variável analisa o efeito da presença de outras marcas de posição linear no SN anteriores ao item analisado, buscando identificar se há alguma influência em relação à marcação de pluralidade. Ou seja, objetiva verificar se as marcas antecedentes inibem ou favorecem o uso da marca formal nos demais itens do sintagma.

Scherre $(1988,1989,2001)$ identificou maior favorecimento de marcação da posição linear em itens precedidos por outros itens com marcação, enquanto que os itens não marcados levaram a não marcação dos itens subsequentes. De acordo com a autora, esse fato deve-se ao processamento paralelo, no qual, atua sobre o princípio: marcas levam a marcas e zeros levam a zeros (cf. Scherre, 1988). 
No intuito de verificar o efeito dessa variável nas Cartas Marienses, reparte-se a variável da seguinte forma: (i) Ausência de marca formal na $1^{a}$ posição (item analisado na $2^{\mathrm{a}}$ posição), (ii) Presença de marca formal na $1^{a}$ posição (item analisado na $2^{\mathrm{a}}$ posição), (iii) Numeral, (iv) Mistura de marcas precedentes com marca formal (item analisado na $3^{\mathrm{a}}$ posição em diante), (v) Mistura de marcas precedentes com zero (item analisado na $3^{\mathrm{a}}$ posição em diante), (vi) Ausência de marcas precedentes (item analisado na $3^{\mathrm{a}}$ posição em diante). Os exemplos, a seguir, retirados das Cartas Marienses, esboçam esses itens.

(i) Ausência de marca formal na $1^{\mathrm{a}}$ posição (item analisado na $2^{\mathrm{a}}$ posição)

a) [...] ouvido parecia namorados dizia | algumaØ pessoas (MJPS, C-51)

b) Aceite umØ forteØ abraços dos seus velhos [...] (MJPS, C-49)

(ii) Presença de marca formal na $1^{\mathrm{a}}$ posição (item analisado na $2^{\mathrm{a}}$ posição)

a) Venho muito respeitozamente | por meio destas linhas lhe [...]( FP, C-1)

b) [...] fim desta $\mid$ e para dar as minhaØ noticia i ao mesmo [...] (EMO, C-58)

(iii) Numeral

a) $[\ldots]$ bem, passou $2 \underline{2}$ semanas aqui com [...].(JPS, C-6)

b) Eu lhe dezejo mil vezØ tudo aquilo que você me[...] (MZNM, C-69)

(iv) Mistura de marcas precedentes com marca formal (item analisado na $3^{\text {a }}$ posição em diante)

a) Ita manda as cadeiras usadas que prometeu-me [...] (MJPS, C-51)

b) Que Jesus lhe ilumine todos seus |caminhoØ (MNM*, C-80)

(v) Mistura de marcas precedentes com zero (item analisado na $3^{\mathrm{a}}$ posição em diante):

a) E Caio colocando as musicaØ | velhas . Teu pae não [...] (MJPS, C-49)

b) [...] de Bom pra VoCe ... Seja |Feliz noØ seus estudoØ. (JCRB, C- 84) 


\begin{tabular}{|c|c|}
\hline $\begin{array}{l}\text { Web Revista } \\
\text { ODIALETO }\end{array}$ & $\begin{array}{c}\text { Núcleo de Pesquisa e Estudos Sociolinguísticos e Dialetológicos - NUPESD } \\
\text { Laboratório Sociolinguístico de Línguas Não-Indo-europeias e Multilinguismo - LALIMU } \\
\text { ISSN: 2178-1486 • Volume } 11 \bullet \text { Número 33 } \text { Mar 2021 } \\
\text { d } 11 \text { http://dx.doi.org/ } 10.48211 / \text { sociodialeto.vlli33.34l }\end{array}$ \\
\hline
\end{tabular}

(vi) Ausência de marcas precedentes (item analisado na $3^{\text {a }}$ posição em diante):

a) Aceite umØ forte $\emptyset$ abraços dos seus velhos [...] (MJPS, C-49)

Gráfico 9: Efeito da variável marcas precedentes na variação na concordância de número nos SNs.

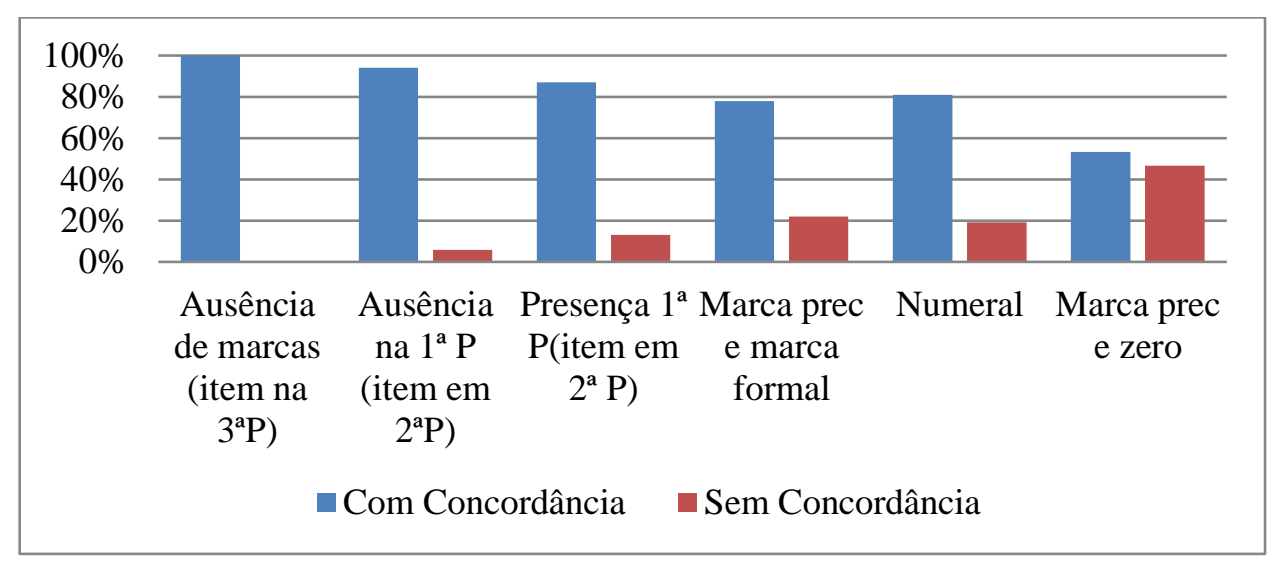

Fonte: Elaborado pela autora.

Observa-se que a ausência de marca formal na $1^{\mathrm{a}}$ posição favorece a marcação da segunda posição, com uma porcentagem de 94.1\%, evidenciando alto índice de marcação. Quando há a presença de marca formal na primeira posição percebe-se um desfavorecimento em relação aos itens que apresentaram ausência na primeira posição. No entanto, observa-se um índice alto de marcas formais com 86.9 pontos percentuais. A presença de numeral mostrou-se significativa para a marcação, no entanto com um índice menor que ausência e presença de marca na $1^{\mathrm{a}}$ posição, exibindo marcas em $80.9 \%$ dos casos.

Com relação à ausência de marcas precedentes tendo como item analisado a $3^{\mathrm{a}}$ posição, houve apenas um caso, no qual obteve a marca de plural. Nas demais circunstâncias, mistura de marcas precedentes com formal tendo como item analisado a $3^{\mathrm{a}}$ posição obteve a marca de plural em $78 \%$ dos itens analisados, ao passo que, a mistura de marcas precedentes com zero e $3^{\text {a }}$ posição analisada obteve um total de 53.3\% de marcas de plural, mostrando que há uma tendência ao desfavorecimento das marcas de plural. Os dados apresentados no gráfico revelam que o princípio marcas levam a marcas e zeros levam a zeros não se aplica às Cartas Marienses. 


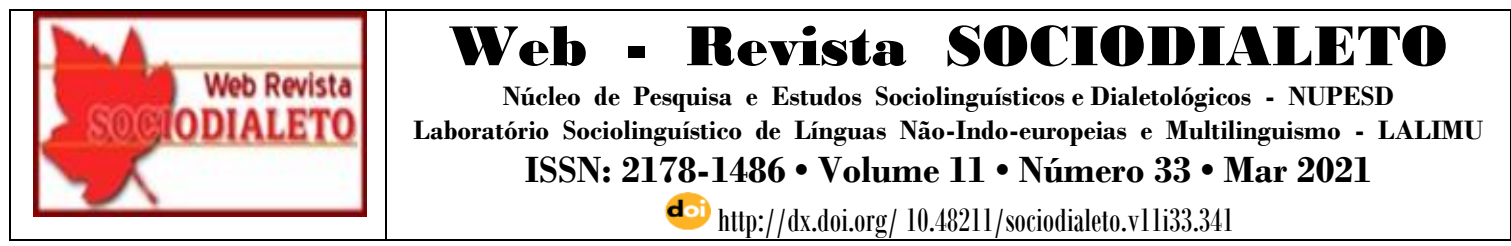

\subsubsection{Variáveis sociais}

Nessa perspectiva de análise as variáveis sociais selecionadas foram: (i) situação de aprendizagem, (ii) presença/ausência do constituinte em fórmulas e (iii) gênero.

\subsubsection{Situação de aprendizagem}

Busca-se observar o efeito dessa variável sobre a presença de marcas de pluralidade nos constituintes dos SNs. Para isso, repartiu-a em quatro grupos de subfatores: aqueles que aprenderam a ler e escrever em ambientes extraescolares, aqueles que estudaram os primeiros anos (primário), aqueles que estudaram até a $8^{a}$ série (Fundamental II), e finalmente aqueles que concluíram o ensino médio.

Gráfico 10: Efeito da situação de aprendizagem sobre a realização da concordância de número nos itens do SN

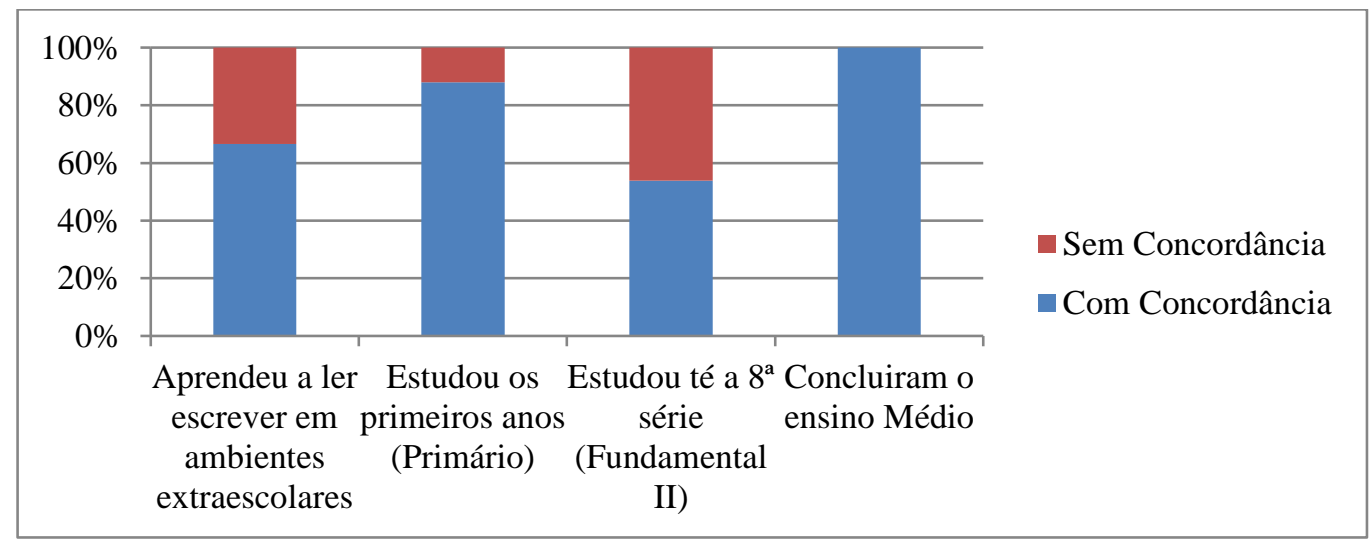

Fonte: Elaborado pela autora

Conforme mostram os resultados, observa-se que os remetentes que realizaram maior marcação de pluralidade nos elementos dos SNs foram àqueles indivíduos que concluíram o ensino médio, exibindo $100 \%$ de marcação, ou seja, uma marca categórica. Em seguida, aparecem aqueles que estudaram os primeiros anos/ nível 
primário, marcando $87.9 \%$ pontos percentuais, dos elementos analisados. Aqueles remetentes que aprenderam a ler e escrever em ambientes extraescolares mostraram-se favorecedores da concordância em $66.6 \%$. O grupo que estudou até a $8^{\mathrm{a}}$ série ou fundamental II aparece como o que mais desfavoreceu a aplicação da regra canônica, com $53.8 \%$ dos dados analisados.

Os remetentes que tiveram maior exposição à educação formal, como é o caso dos remetentes que concluíram o ensino médio, adquiriram as regras gramaticais disseminadas pela escola, exibindo todas as marcas formais de concordância nominal. Os remetentes que possuem o ensino fundamental II, antiga $8^{\mathrm{a}}$ série, foi o grupo de fatores que mais desfavoreceu a aplicação da regra, abaixo daqueles que aprenderam a ler e escrever em ambientes extraescolares e, também daqueles remetentes que estudaram apenas o nível primário. Entre outras explicações possíveis, este fato pode estar associado ao processo de ensino irregular e precário ao qual foram expostos. Como afirmam Carneiro e Almeida (2006), o processo de escolarização no interior baiano foi tardio, irregular e precário, os quais refletem na aprendizagem dos alunos.

\subsubsection{Presença/ausência do constituinte em fórmulas}

A variável presença/ausência em fórmulas tem o intuito de observar o efeito da variação em fórmulas cristalizadas nos constituintes do SN. Como já visto no item anterior (5.1.2.2), há a presença dessas construções no corpus analisado, como mostram os exemplos que seguem:

(i) Constituintes marcados presentes nas fórmulas

a) Envio-te estas duas Linhas para $\mid$ saber das tuas noticías e ao | (Z, C-54)

(ii) Constituintes não marcados presente nas fórmulas

a) [...] escrevo essas duas linha $\varnothing \mid$ e para dar as milnhas [...] (MSJ, C-61) 


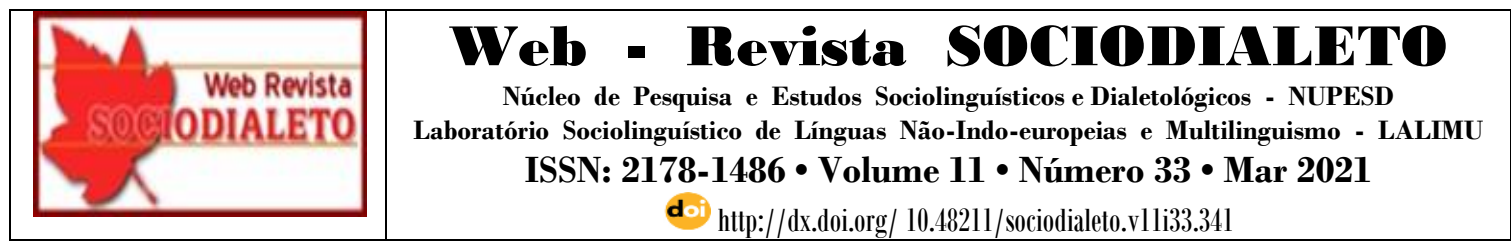

Os resultados mostram que dos 774 constituintes analisados $66(8,52 \%)$ residem em fórmulas e, $708(91,47)$ fora das fórmulas. Destes 66 analisados, $52(78.7 \%)$ foram marcados formalmente, ao passo que os outros 14 (21.2\%), não receberam a marcação de concordância de plural. Constata-se que houve altos índices de marcação, tanto para os constituintes presentes em fórmulas como para os constituintes que estão fora das fórmulas.

Gráfico 11: Efeito da variável Presença/Ausência em fórmulas sobre a realização da concordância de número nos itens do SN.

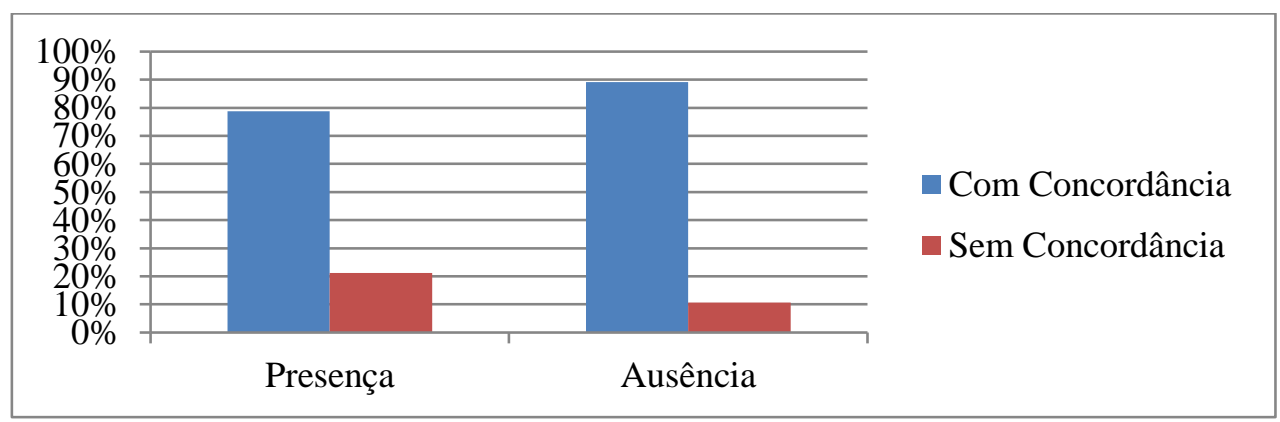

Fonte: Elaborado pela autora.

Os dados mostram que a cristalização das fórmulas no corpus é parcial, uma vez que há variação na aplicação da regra de concordância nominal de número nos itens analisados. Como observado na análise sintagmática, às fórmulas apresentam flexibilidade com relação à marcação de plural, já que há itens em processo de variação.

\subsubsection{Gênero}

Repartiu-se a variável em dois fatores: 1) feminino, e 2) masculino. Seguem- se construções que exemplificam esses contextos:

\section{Feminino}

a) [...] menina de Bato| vem todos os dias faz as rumação [...](MNPS, C-12)

b) [...] Ano Novo|...| de muitas FelicidadeØ Da Comadre [...] (AJNM, C- 77) 


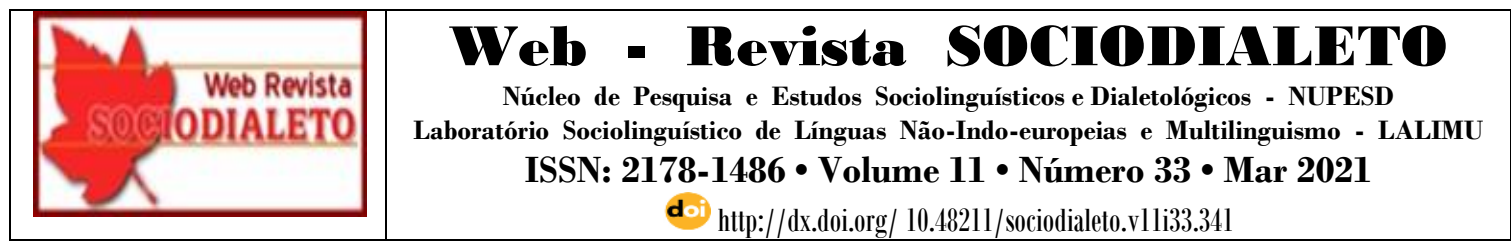

\section{Masculino}

a) Com referensa a seos fumos, peço favor de chegar [...].(M, C-3)

b) $[\ldots]$ lhe escrevo esta $\emptyset$ duas linhaØ (AOS, C-60

Há altos índices de marcação de pluralidade na variável analisada. Com relação aos dados percentuais, os dois fatores analisados apresentaram desempenho similar. $\mathrm{O}$ gênero masculino exibiu $88.7 \%$ de marcas percentuais, enquanto que o gênero feminino exibiu 88,2.

Gráfico 12: Efeito da variável Gênero sobre a variação da concordância de número nos itens do SNs

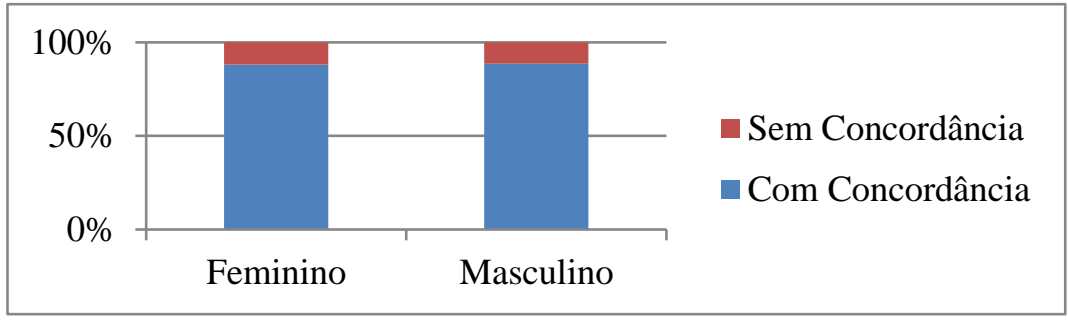

Fonte: Elaborado pela autora.

O gênero masculino favoreceu minimamente a aplicação da regra de concordância em relação ao gênero feminino. Pode-se afirmar que não houve diferenças significativas em relação aos fatores analisados. Os homens e as mulheres aplicaram a regra formal de concordância de forma nivelada.

\section{CONSIDERAÇÕES FINAIS}

O contato dos colonizadores portugueses com milhões de aloglotas, falantes de milhares de línguas indígenas autóctones e as cercas de duzentas línguas africanas trazidas para cá por conta da escravidão, como afirma Lucchesi (2009, p. 41), “é o principal parâmetro histórico para a contextualização das mudanças linguísticas que afetaram o português brasileiro”. A concordância nominal de número figura como um 
dos principais aspectos morfossintáticos do $\mathrm{PB}$ que sofreu drásticas alterações gramaticais, sobretudo em decorrência do processo de transmissão linguística irregular ocorrido no país nos três primeiros séculos de colonização portuguesa. Por isso, é ao lado da concordância verbal um dos fenômenos mais estigmatizados socialmente e por consequência um dos mais investigados pela sociolinguística laboviana.

Tendo em vista o fato de este fenômeno ser bastante investigado, principalmente em corpora orais, este trabalho buscou contribuir com as pesquisas sobre o fenômeno realizando o estudo tanto em uma perspectiva sintagmática como atomística em um corpus esteado em textos escritos de sincronias passadas.

A análise dos dados mostrou que a concordância nominal de número no $\mathrm{SN}$ no corpus é condicionada por fatores de ordem linguística e social.

Na perspectiva sintagmática: há uma predominância das marcas canônicas nos SNs passíveis de receber a concordância nominal de número plural. Dos 337 SNs, 77,4 obtiveram a marcação de plural.

i. A posição do SN com relação ao verbo interfere na exibição de marcas. Confirma-se a hipótese de que, os sintagmas à esquerda do verbo tendem a favorecer a aplicação da regra canônica de concordância.

ii. Os sintagmas compostos por dois itens tendem a ser mais marcados, indicando que os sintagmas com menor extensão apresentam maiores índices de marcação.

iii. $\quad$ O nível de escolaridade exerce influência com relação à aplicação da regra formal, sendo que a qualidade do ensino-aprendizagem contribui para o desempenho.

iv. As expressões cristalizadas não constituem espaços de resistências às variações.

v. Os homens exercem, modestamente, maior influência em relação às marcas explícitas de plural 
Na perspectiva atomística: há um predomínio com relação às marcas explícitas nos constituintes analisados. Dos 773 constituintes 88,4 \% obedeceram a regra canônica de concordância.

i. A posição à esquerda adjacente ao núcleo exerce forte influência à marcação de pluralidade nos itens do SN, exibindo uma marca semicategórica de marcação com 95,5\%. Já a posição à direita do núcleo foi a que mais desfavoreceu com $58,8 \%$.

ii. Na escala da saliência na dimensão maior ou menor oposição de substância fônica entre as formas singular/plural, os itens mais salientes obtiveram maior marcas explícitas de plural, que àqueles menos salientes. Quanto aos processos e tonicidade conclui-se que os itens formados por oxítonos e monossílabos exercem maior influência em relação aos paroxítonos e proparoxítonos, que são menos salientes.

iii. O princípio marcas levam a marcas e zeros levam a zeros não se aplica ao corpus Cartas Marienses. Nos itens que há ausência de marcas precedentes houve altos índices de marcação, ao contrário dos itens com presença de marcas precedentes que houve um leve desfavorecimento.

iv. Os remetentes que tiveram maior exposição à educação formal adquiriram as marcas formais disseminadas pela escola, exibindo todas as marcas formais de concordância, ou seja, uma marca categórica.

v. As fórmulas cristalizadas apresentam variação em relação à concordância de número.

vi. Sobre a variável gênero conclui-se que não houve diferenças significativas em relação aos fatores analisados. Homens e mulheres aplicam a regra de forma equiparada. 


\section{REFERÊNCIAS}

BARBOSA, Afrânio Gonçalves. Para uma história do português colonial: aspectos linguísticos em cartas do comércio. Tese (Doutorado em Letras Vernáculas) Universidade Federal do Rio de Janeiro, Rio de Janeiro, 1999, p. 134-204.

BECHARA, E. Moderna gramática portuguesa. São Paulo: Companhia Editora Nacional, 1999.

BRANDÃO. Silvia Figueiredo. Concordância nominal. In: VIEIRA. Silvia Rodrigues, BRANDÃO. Silvia Figueiredo. Ensino de gramática: descrição e uso. São Paulo: Contexto, 2016.

BRITO, Patrícia Santos de Jesus. Cartas Marienses (Séc. XX): Edição semidiplomática e fac-similar e estudo da concordância nominal. Dissertação (Mestrado em Linguística) - Universidade Estadual de Feira de Santana, 2020.

CARNEIRO, Zenaide de Oliveira Novais; ALMEIDA, Norma Lúcia Fernandes de. A criação de escolas a partir de critérios demográficos na Bahia do século XIX: uma viagem ao interior. In: LOBO, Tânia; RIBEIRO, Ilza; CARNEIRO, Zenaide (Org.). Para a História do Português Brasileiro: novos dados, novas análises. Salvador: EDUFBA, 2006. v. 2. p. 649-673.

LEMLE, M.; NARO, A. J. Competências básicas do português. (Relatório final de pesquisa apresentado às instituições patrocinadoras Fundação Movimento Brasileiro de Alfabetização - MOBRAL e Fundação Ford). Rio de Janeiro, 1977.

LOPES, N.S. Concordância nominal, contexto lingüístico e sociedade. 2001. Tese (Doutorado em Letras e Linguística) - Instituto de Letras, Universidade Federal da Bahia, Salvador.

LUCCHESI, Dante. As duas grandes vertentes da história Sociolinguística do Brasil (1500-2000). DELTA. São Paulo, v. 17, n. 1, p. 97-132, 2001.

LUCCHESI, Dante. Parâmetros sociolinguísticos do português brasileiro. Revista da ABRALIN, v. 5, n. 1 e 2, 2006, p. 83-112.

LUCCHESI, Dante; BAXTER, Alan. A transmissão linguística irregular. In: LUCCHESI, Dante; BAXTER, Alan; RIBEIRO, Ilza (Org.). O português afrobrasileiro. Salvador: EDUFBA, 2009. p. 101-124.

LUCCHESI, Dante. Língua e sociedade partidas: a polarização sociolinguística do Brasil. São Paulo: Contexto, 2015.

MATTOS E SILVA, Rosa Virgínia. Ensaios para uma sócio-história do português brasileiro. São Paulo: Parábola Editorial, 2004.

MATTOS E SILVA, Rosa Virgínia. Caminhos da Linguística Histórica: ouvir o inaudível. São Paulo: Parábola Editorial, 2008. p.7-26. 


\begin{tabular}{|c|c|}
\hline $\begin{array}{r}\text { Web Revista } \\
\text { ODIALETO }\end{array}$ & 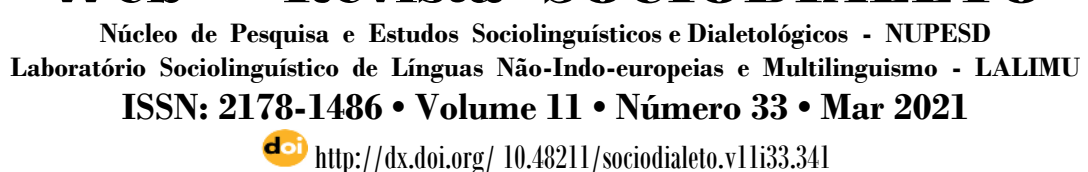 \\
\hline
\end{tabular}

NARO, A. J. The social and structural dimensions of a syntactic change. Language, v. 57, n. 1, 1981, p. 63-98.

SCHERRE, Maria Marta Pereira. Reanálise da concordância nominal em português. 1988.2 v. 555 f. (Mimeo). Tese (Doutorado em Linguística) - Faculdade de Letras, Universidade Federal do Rio de Janeiro, Rio de Janeiro, 1988.

SCHERRE, Maria Marta Pereira. Concordância nominal e funcionalismo. Alfa, São Paulo, 41(n.esp), 1997. p. 181-206.

SOUZA, V.; COELHO, J. S. B. Concordância nominal (cenas da variação em palcos do século XIX). In: LOBO, T. C. F. (Org.). África à vista: dez estudos sobre o português escrito por africanos no Brasil do século XIX. Salvador: EDUFBA, 2009. p. 255-316.

WEINREICH, U.; LABOV, W.; HERZOG, M. I. Fundamentos empíricos para uma teoria da mudança linguística. São Paulo: Parábola, 2006. [1968]

Recebido em: 23/10/2020 | Aprovado em: 09/01/2021. 


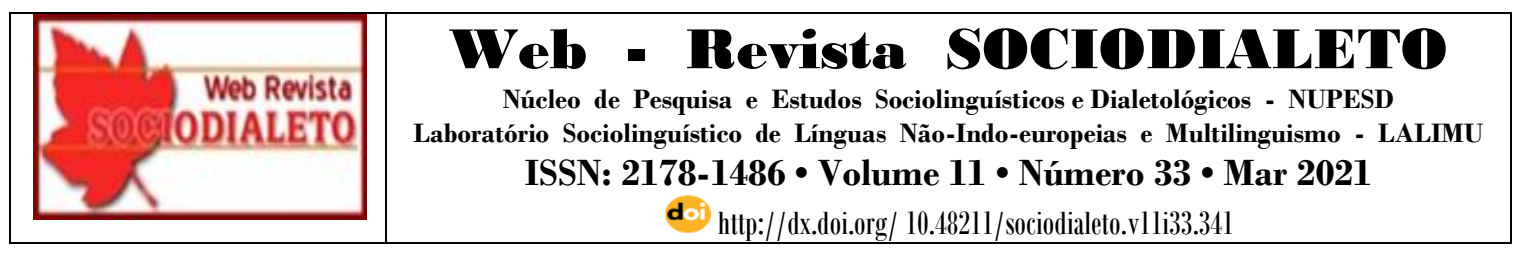

